\section{Response to: 'Assessment of responsiveness of the musculoskeletal component of SLE-DAS in an independent cohort', by Hassan et al}

It was with great interest that we read the letter 'Assessment of responsiveness of the musculoskeletal component of SLE-DAS in an independent cohort' by Hassan et al. ${ }^{1}$

We recently published the derivation and validation of the Systemic Lupus Erythematosus Disease Activity Score (SLEDAS), a new continuous measure of SLE disease activity with high sensitivity and specificity to change. ${ }^{2}$

Hassan et al report in their letter that in an analysis of 20 SLE patients, the responsiveness of the arthritis component of SLE-DAS (large effect size of -0.548 ) is superior to that of the arthritis component of SLE Disease Activity Index (DAI)-2K (medium effect size of -0.418 ). ${ }^{13}$ These results corroborate our data. ${ }^{24}$ Moreover, Hassan et al report that the arthritis component of SLE-DAS presents a similarly large effect size comparing with the arthritis component of the British Isles Lupus Assessment Group (BILAG) (-0.576). As highlighted by Hassan et al, the SLE-DAS is expected to present a more robust inter-reader reliability than physician visual analogue scale and BILAG, and to be less dependent on the training and expertise of the assessors than BILAG.

We further emphasise that SLE-DAS is a global disease activity index (non-organ specific), which presents a major advantage over BILAG for use in daily clinical practice, as it is much less time-consuming and requires a collection time similar to SLEDAI.

Hassan et al report that joint ultrasonography (US) is able to detect subclinical synovitis in SLE patients. We agree that in selected patients joint US can be useful to complement clinical assessment. However, the requirement for US joint assessment is not advisable to integrate a disease activity instrument, such as SLE-DAS, as it would constitute a major barrier for its practicality. Importantly, previous studies did not find any added value of systematic joint US assessment for treatment decision in chronic arthritis. ${ }^{5-7}$

In summary, this letter by Hassan et al corroborates the improved responsiveness of the arthritis component of SLE-DAS in an independent longitudinal cohort. The relative sensitivity and specificity of SLE-DAS and BILAG will be further tested in our upcoming study comparing BILAG and SLE-DAS.

Diogo Jesus $\odot,^{1,2}$ Margherita Zen, ${ }^{3}$ Andrea Doria $\odot{ }^{3}$ Luís Sousa Inês ${ }^{1,2}$
${ }^{1}$ Rheumatology Department, Centro Hospitalar e Universitario de Coimbra EPE, Coimbra, Portugal

${ }^{2}$ School of Health Sciences, University of Beira Interior, Covilhã, Portugal

${ }^{3}$ Rheumatology Unit, Department of Medicine, University of Padova, Padova, Italy

Correspondence to Dr Diogo Jesus, Serviço de Reumatologia, Centro Hospitalar e Universitário de Coimbra, Coimbra, Portugal; Jesus.p.diogo@gmail.com

Handling editor Josef S Smolen

Competing interests None declared.

Patient consent for publication Not required.

Provenance and peer review Commissioned; internally peer reviewed.

(C) Author(s) (or their employer(s)) 2020. No commercial re-use. See rights and permissions. Published by BMJ.

\section{Check for updates}

To cite Jesus D, Zen M, Doria A, et al. Ann Rheum Dis 2020;79:e52.

Received 2 April 2019

Accepted 2 April 2019

Published Online First 25 April 2019

\section{SLinked}

- http://dx.doi.org/10.1136/annrheumdis-2019-215411

Ann Rheum Dis 2020;79:e52. doi:10.1136/annrheumdis-2019-215430

ORCID iDs

Diogo Jesus http://orcid.org/0000-0003-3136-0722

Andrea Doria http://orcid.org/0000-0003-0548-4983

\section{REFERENCES}

1 Hassan S, Mahmoud K, Vital E. Assessment of responsiveness of the musculoskeletal component of SLE-DAS in an independent cohort. Ann Rheum Dis 2020;79:e51.

2 Jesus D, Matos A, Henriques C, et al. Derivation and validation of the SLE disease activity score (SLE-DAS): a new SLE continuous measure with high sensitivity for changes in disease activity. Ann Rheum Dis 2019;78:365-71.

3 Mahmoud $K$, Zayat AS, Yusof $Y$, et al. Responsiveness of clinical and ultrasound outcome measures in musculoskeletal systemic lupus erythematosus. Rheumatology 2019;62.

4 Jesus D, Rodrigues M, Matos A, et al. Performance of SLEDAI-2K to detect a clinically meaningful change in SLE disease activity: a 36-month prospective cohort study of 334 patients. Lupus 2019;35.

5 Dale J, Stirling A, Zhang R, et al. Targeting ultrasound remission in early rheumatoid arthritis: the results of the TaSER study, a randomised clinical trial. Ann Rheum Dis 2016;75:1043-50.

6 Haavardsholm EA, Aga A-B, Olsen IC, et al. Ultrasound in management of rheumatoid arthritis: Arctic randomised controlled strategy trial. BMJ 2016;354.

7 Aletaha D, Smolen JS. Achieving clinical remission for patients with rheumatoid arthritis. JAMA 2019;321:457-8. 